\title{
Characteristics of Tumor-Infiltrating Lymphocytes Prior to and During Immune Checkpoint Inhibitor Therapy
}

\author{
loana Plesca ${ }^{1}$, Antje Tunger ${ }^{1,2}$, Luise Müller ${ }^{1}$, Rebekka Wehner ${ }^{1,2,3}$, Xixi Lai' \\ Marc-Oliver Grimm ${ }^{4}$, Sergio Rutella ${ }^{5}$, Michael Bachmann ${ }^{2,3,6}$ and Marc Schmitz, 1,2,3* \\ ${ }^{1}$ Faculty of Medicine Carl Gustav Carus, Institute of Immunology, TU Dresden, Dresden, Germany, ${ }^{2}$ National Center \\ for Tumor Diseases (NCT), Partner Site Dresden, Dresden, Germany, ${ }^{3}$ German Cancer Consortium (DKTK), Partner Site \\ Dresden, German Cancer Research Center (DKFZ), Heidelberg, Germany, ${ }^{4}$ Department of Urology, Jena University Hospital, \\ Jena, Germany, ${ }^{5}$ John van Geest Cancer Research Center, College of Science and Technology, Nottingham Trent University, \\ Nottingham, United Kingdom, ${ }^{6}$ Department of Radioimmunology, Institute of Radiopharmaceutical Cancer Research, \\ Helmholtz Center Dresden-Rossendorf, Dresden, Germany
}

\section{OPEN ACCESS}

Edited by:

Ulrich Sack,

Leipzig University, Germany

Reviewed by:

Catherine Sautes-Fridman INSERM U1138 Centre de Recherche des Cordeliers, France

Per thor Straten,

Herlev Hospital, Denmark

${ }^{*}$ Correspondence: Marc Schmitz

marc.schmitz@tu-dresden.de

Specialty section:

This article was submitted to Cancer Immunity and Immunotherapy, a section of the journal

Frontiers in Immunology

Received: 12 December 2019

Accepted: 14 February 2020

Published: 04 March 2020

Citation:

Plesca I, Tunger A, Müller L, Wehner R, Lai X, Grimm M-O,

Rutella S, Bachmann M and Schmitz M (2020) Characteristics of Tumor-Infiltrating Lymphocytes

Prior to and During Immune

Checkpoint Inhibitor Therapy.

Front. Immunol. 11:364. doi: 10.3389/fimmu.2020.00364
The tumor immune contexture plays a major role for the clinical outcome of patients. High densities of $\mathrm{CD}^{2} 5 \mathrm{RO}^{+} \mathrm{T}$ helper 1 cells and $\mathrm{CD}^{+} \mathrm{T}$ cells are associated with improved survival of patients with various cancer entities. In contrast, a higher frequency of tumor-infiltrating M2 macrophages is correlated with poor prognosis. Recent studies provide evidence that the tumor immune architecture also essentially contributes to the clinical efficacy of immune checkpoint inhibitor (CPI) therapy in patients. Pretreatment melanoma samples from patients who experienced a clinical response to antiprogrammed cell death protein 1 (PD-1) treatment show higher densities of infiltrating $\mathrm{CD}^{+} \mathrm{T}$ cells compared to samples from patients that progressed during therapy. Anti-PD-1 therapy results in an increased density of tumor-infiltrating $T$ lymphocytes in treatment responders. In addition, elevated frequencies of melanoma-infiltrating $\mathrm{TCF} 7^{+} \mathrm{CD}^{+} \mathrm{T}$ cells are correlated with beneficial clinical outcome of anti-PD-1-treated patients. In contrast, a high density of tumor-infiltrating, dysfunctional $\mathrm{PD}-1+\mathrm{CD} 38^{\text {hi }}$ $\mathrm{CD}^{+}$cells in melanoma patients is associated with anti-PD-1 resistance. Such findings indicate that comprehensive tumor immune contexture profiling prior to and during $\mathrm{CPI}$ therapy may lead to the identification of underlying mechanisms for treatment response or resistance, and the design of improved immunotherapeutic strategies. Here, we focus on studies exploring the impact of intratumoral $\mathrm{T}$ and $\mathrm{B}$ cells at baseline on the clinical outcome of CPI-treated cancer patients. In addition, recent findings demonstrating the influence of CPIs on tumor-infiltrating lymphocytes are summarized.

Keywords: cancer immunotherapy, immune architecture, immune monitoring, immune checkpoint inhibition, cytotoxic T lymphocyte antigen 4, programmed cell death protein 1, programmed cell death 1 ligand 1

\section{INTRODUCTION}

Accumulating evidence indicates that the tumor immune contexture plays a critical role for the clinical outcome of cancer patients (1-4). Major components of the tumor immune architecture are $\mathrm{CD} 8^{+}$and $\mathrm{CD} 4^{+} \mathrm{T}$ cells that can essentially contribute to tumor elimination. Activated $\mathrm{CD} 8^{+}$ $\mathrm{T}$ cells produce large amounts of proinflammatory cytokines such as tumor necrosis factor (TNF)- $\alpha$ 
and interferon (IFN)- $\gamma$ and exhibit a profound tumor-directed cytotoxicity. Stimulated $\mathrm{CD} 4^{+} \mathrm{T}$ cells secrete various cytokines that promote the differentiation of $\mathrm{B}$ cells into antibodyproducing plasma cells (5). They also enhance the capacity of dendritic cells (DCs) to induce $\mathrm{CD} 8^{+} \mathrm{T}$ cell responses and can eliminate tumor cells directly (5). When analyzing the clinical relevance of tumor-infiltrating $\mathrm{T}$ cells, it has been demonstrated that high densities of $\mathrm{CD}^{+}$memory $\mathrm{T}$ helper $\left(\mathrm{T}_{\mathrm{H}}\right) 1$ cells and $\mathrm{CD}^{+} \mathrm{T}$ cells are associated with improved disease-free and overall survival (OS) of colorectal cancer patients $(6,7)$. Recently, a multi-center study has been initiated to assess the prognostic value of tumor-infiltrating $\mathrm{T}$ cell numbers in colon cancer patients (8). Patients with a so-called high Immunoscore, which is characterized by a high frequency of $\mathrm{CD}^{+}$and $\mathrm{CD} 8^{+} \mathrm{T}$ cells in the tumor center and the invasive margin, had the longest survival and the lowest risk of recurrence (8). These results suggest that the Immunoscore may represent a reliable estimate of the risk of disease recurrence and support its implementation in the classification of colon cancer. In addition to colorectal cancer patients, a correlation between high densities of $\mathrm{T}_{\mathrm{H}} 1$ cells or $\mathrm{CD}^{+} \mathrm{T}$ cells and good prognosis has also been reported for patients with other cancer entities $(1,3)$.

Macrophages and DCs are other key components of the tumor immune contexture that can profoundly influence tumor growth and spreading. Macrophages can be classified according to their phenotype and functional properties $(9,10)$. M1 macrophages, which express high levels of proinflammatory mediators such as TNF- $\alpha$, interleukin (IL)- $1 \beta$, reactive oxygen species, and nitric oxide, act in a tumoricidal manner. Based on their tumor-directed properties, M1 macrophages are generally associated with a favorable clinical outcome of cancer patients $(1,3)$. In contrast, M2 macrophages, which are characterized by the release of proangiogenic mediators such as vascular endothelial growth factor (VEGF) and immunosuppressive cytokines such as IL-10 and transforming growth factor- $\beta$, are generally correlated with poor prognosis among cancer patients $(1,3)$. DCs display an extraordinary capacity to induce and regulate $\mathrm{T}$ cell responses and efficiently enhance the immunomodulatory and cytotoxic potential of natural killer (NK) cells (11). Due to these functional capabilities, DCs play a major role in antitumor immunity. When investigating the clinical impact of blood DC subsets, it has been demonstrated that a higher expression of specific gene signatures for myeloid DC1 and DC2 as well as for plasmacytoid DCs are associated with a higher probability for disease-free survival of patients with luminal breast cancer (12). Furthermore, a higher DC1specific gene signature was significantly associated with improved survival in patients with various cancer entities (13). However, tumor-infiltrating DCs can also be defective in their functional activity and can contribute to immune suppression (14). For example, we have shown that a higher density of 6-sulfo LacNAc monocytes (slanMo), representing a subset of human non-classical blood monocytes that can differentiate into DCs (15), is significantly associated with a poor prognosis of clear cell renal cell cancer (RCC) patients (16). The tumor-infiltrating slanMo displayed an immature phenotype and expressed IL-10, which may explain this correlation.

Recent studies revealed that the tumor immune contexture also essentially contributes to the clinical efficacy of immune checkpoint inhibitor (CPI) therapy that evolved as a very promising treatment modality for cancer patients (17). Antibody-mediated blockade of the immune checkpoint receptors cytotoxic $\mathrm{T}$ lymphocyte antigen 4 (CTLA-4), programmed cell death protein 1 (PD-1) or programmed cell death 1 ligand 1 (PD-L1) resulted in objective clinical responses and enhanced survival of cancer patients (18-20). Here, the current knowledge about the impact of intratumoral $\mathrm{T}$ and $\mathrm{B}$ cells at baseline on the clinical outcome of CPI-treated patients and treatment-mediated effects on tumor-infiltrating lymphocytes is summarized.

\section{CHARACTERISTICS OF INTRATUMORAL T CELLS PRIOR TO AND DURING ANTI-CTLA-4 THERAPY}

\section{Function and Therapeutic Targeting of CTLA-4}

Cytotoxic $\mathrm{T}$ lymphocyte antigen 4 is a member of the immunoglobulin superfamily, which is induced on the surface of $\mathrm{T}$ cells by antigen binding to the $\mathrm{T}$ cell receptor (21-23). CTLA-4 competes with CD28 for binding to $\mathrm{CD} 80$ or CD86 on professional antigen-presenting cells (APCs). Thereby it binds CD80 and CD86 more tightly than $\mathrm{CD} 28$ and delivers a negative signal, which dampens the early $\mathrm{T}$ cell activation. CTLA- 4 regulates the amplitude of $\mathrm{CD}^{+} \mathrm{T}$ cell priming and also the $\mathrm{CD}^{+} \mathrm{T}$ cell help for the induction of $\mathrm{CD}^{+} \mathrm{T}$ cell responses in lymphoid tissues. CTLA-4 is constitutively expressed on regulatory $\mathrm{T}\left(\mathrm{T}_{\text {reg }}\right.$ ) cells, enhancing their immunosuppressive activity (24). Accordingly, CTLA-4 blockade fosters the expansion, cytokine secretion, and cytotoxic potential of $\mathrm{T}$ effector cells and inhibits the immunosuppressive activity of $\mathrm{T}_{\text {reg }}$ cells, resulting in improved antitumor responses. Therefore, CTLA-4 blockade is an attractive immunotherapeutic strategy to significantly enhance effector $\mathrm{T}$ cell-mediated antitumor immunity (25). Two phase III clinical trials have been conducted to explore the therapeutic efficacy of the antiCTLA-4 monoclonal antibody ipilimumab. Melanoma patients treated with ipilimumab with or without a glycoprotein 100 peptide vaccine showed significantly improved OS compared to patients receiving the peptide vaccine alone (26). Furthermore, the combination of the DNA-alkylating agent dacarbazin with ipilimumab led to improved OS in melanoma patients compared to dacarbazin alone (27). Based on these clinical trials, ipilimumab was approved by the United States Food and Drug Administration (FDA) for the treatment of patients with metastatic melanoma in 2011 (28). 


\section{Correlation Between Frequency and Phenotype of Intratumoral T Cells and Clinical Efficacy of CTLA-4 Blockade}

Recently, the association between immunological parameters in tumor tissues at baseline and the clinical activity of anti-CTLA-4 therapy has been explored. Surprisingly, Hamid et al. found a positive correlation between clinical efficacy of CTLA- 4 blockade and a high baseline expression of either the $\mathrm{T}_{\text {reg }}$ cell-associated transcription factor FoxP3 or the immunosuppressive molecule indoleamine 2,3-dioxygenase (IDO) in melanoma patients (29). Whereas no correlation between the frequency of pre-existing tumor-infiltrating $\mathrm{T}$ cells and clinical activity was observed, an anti-CTLA-4 therapy-mediated increase of the intratumoral $\mathrm{T}$ cell density was associated with improved clinical outcome. Various studies further substantiate the influence of anti-CTLA-4 treatment on the frequency and phenotype of intratumoral $\mathrm{T}$ cells. Thus, CTLA-4 blockade resulted in a significant increase of $\mathrm{CD}^{+} \mathrm{T}$ cells regardless of clinical responses in melanoma patients (30). Hodi et al. observed clinical responses in the majority of metastatic melanoma patients who received ipilimumab after vaccination with irradiated, autologous tumor cells engineered to secrete granulocyte-macrophage colonystimulating factor (GM-CSF) (31). Analysis of posttreatment biopsies from metastatic lesions revealed a relation between the extent of therapy-induced tumor necrosis and the natural logarithm of the ratio of tumor-infiltrating $\mathrm{CD} 8^{+}$effector $\mathrm{T}$ cells to $\mathrm{T}_{\text {reg }}$ cells, suggesting that ipilimumab can alter the balance of effector $\mathrm{T}$ cells and $\mathrm{T}_{\text {reg }}$ cells (31). When investigating anti-CTLA-4 therapy-related effects on the density of tumorinfiltrating $\mathrm{T}_{\text {reg }}$ cells, Sharma et al. found that this treatment does not significantly modulate the frequency of $\mathrm{T}_{\text {reg }}$ cells in patients (32).

In further studies, the impact of anti-CTLA-4 therapy on the phenotype of intratumoral $\mathrm{T}$ cells has been explored. It has been reported that this therapeutic strategy enhances the density of tumor-infiltrating $\mathrm{CD}^{+}{ }^{+} \mathrm{T}$ cells expressing the costimulatory molecule inducible $\mathrm{T}$ cell costimulator (ICOS) (33). In addition, a subset of IFN- $\gamma$-producing $\mathrm{T}$ cells was detected within the $\mathrm{ICOS}^{+} \mathrm{CD}^{+}{ }^{+} \mathrm{T}$ cell population, indicating that anti-CTLA4 therapy can induce a $\mathrm{T}_{\mathrm{H}} 1$ polarization in $\mathrm{CD}^{+}$ effector cells (33). Wei et al. observed an expansion of tumorinfiltrating $\mathrm{ICOS}^{+} \mathrm{T}_{\mathrm{H}}$ 1-like $\mathrm{CD}^{+}{ }^{+} \mathrm{T}$ cells and exhausted-like $\mathrm{CD}^{+} \mathrm{T}$ cells following anti-CTLA-4 blockade in melanoma patients (34). Moreover, an enhanced frequency of melanomainfiltrating $\mathrm{ICOS}^{+} \mathrm{CD}^{+} \mathrm{T}$ cells, sustained over 3 months of anti-CTLA-4 treatment, was associated with better OS (35). When evaluating tissue specimens from prostate cancer patients prior to and after anti-CTLA-4 blockade, Gao et al. detected a higher proportion of tumor-infiltrating $\mathrm{CD} 4^{+} \mathrm{T}$ cells, $\mathrm{CD} 8^{+}$ $\mathrm{T}$ lymphocytes, and $\mathrm{CD}^{+} 8^{+}$macrophages expressing $\mathrm{PD}-\mathrm{L} 1$ or $\mathrm{V}$-domain Ig suppressor of $\mathrm{T}$ cell activation (VISTA), representing another inhibitory immune checkpoint receptor (36), after treatment (37). PD-L1 and VISTA expression on these immune cell subsets may contribute to the poor responsiveness of prostate cancer patients to anti-CTLA-4 therapy. A summary of immune cell characteristics that may have an impact on the clinical efficacy of anti-CTLA-4 therapy is given in Figure 1.

\section{CHARACTERISTICS OF TUMOR-INFILTRATING LYMPHOCYTES PRIOR TO AND DURING ANTI-PD-1/PD-L1 TREATMENT}

\section{Function and Therapeutic Targeting of the PD-1/PD-L1 Axis}

Programmed cell death protein 1 is another immune checkpoint receptor of the immunoglobulin superfamily, which can be found on activated T effector cells, NK cells, and B cells $(18,38)$. PD-1 is also expressed by $\mathrm{T}_{\text {reg }}$ cells and fosters their proliferation after ligand binding (39). PD-L1 and PD-L2 represent the ligands for PD-1, the latter having a higher affinity to PD-1. PD-L1 can be widely detected on tumor cells as well as hematopoietic and non-hematopoietic cells and its expression is inducible by proinflammatory cytokines such as IFN- $\gamma$. PD-L2 is characterized by a more restricted expression pattern, being mainly detectable on APCs and induced mostly by IL-4 and GMCSF (40-43). Besides PD-1, PD-L1 can also bind to CD80 on $\mathrm{T}$ cells, thereby delivering another inhibitory signal (44). The main role of PD-1 is to modulate important functional properties of antigen-experienced effector $\mathrm{T}$ cells within the peripheral tissues. Thus, expansion, cytokine release, and cytotoxic activity of stimulated $\mathrm{T}$ cells are inhibited upon interaction of PD-1 with its ligands, protecting the tissue from collateral damage during immune response (40,45-47). This pathway is adopted by tumors leading to prevention from immune attack. Therefore, anti-PD-1 and anti-PD-L1 antibodies have been developed to enhance $\mathrm{T}$ cell-mediated antitumor immunity. The application of such antibodies induced objective clinical responses and improved survival in cancer patients (48-50). Consequently, the FDA approved anti-PD-1/PD-L1 therapy for various tumor entities $(28,51)$.

\section{Correlation Between PD-L1 Expression by Tumor Cells and Tumor-Infiltrating Immune Cells and Clinical Efficacy of PD-1/PD-L1 Blockade}

Various clinical trials clearly indicated that PD-L1 expression by tumor-infiltrating immune cells and tumor cells significantly influences the efficacy of anti-PD-1/PD-L1 treatment. Accordingly, an association between intratumoral PD-L1 expression in pretreatment tissue specimens and objective clinical responses in anti-PD-1/PD-L1-treated cancer patients has been reported (52). Herbst et al. demonstrated that a high level of intratumoral PD-L1, particularly when detected on tumor-infiltrating immune cells, was associated with clinical responses in anti-PD-L1 antibody-treated cancer patients (53). Topalian et al. observed that 9 of 25 patients with PD-L1 ${ }^{+}$tumors experienced an objective clinical response, whereas none out of 17 patients with $\mathrm{PD}^{-\mathrm{L}^{-}}{ }^{-}$tumors achieved an objective response 


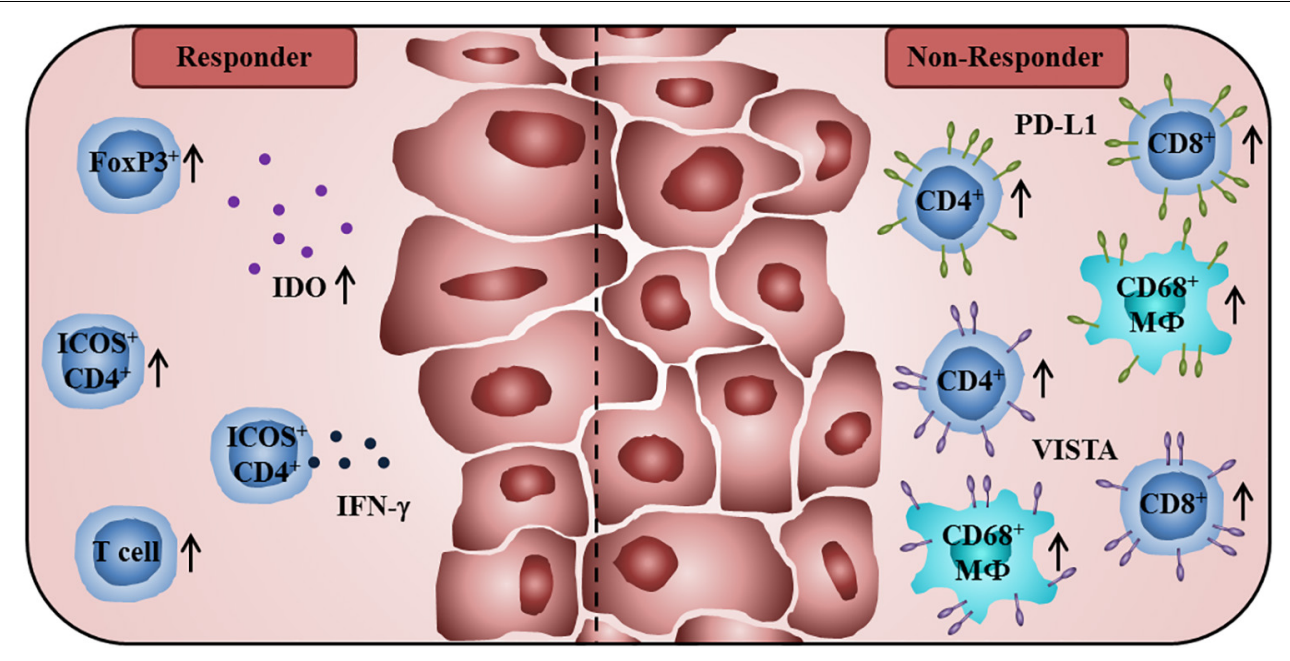

FIGURE 1 | Immunological characteristics of tumor patients receiving anti-CTLA-4 antibodies associated with improved clinical outcome or therapy resistance. A high baseline expression of $T_{\text {reg }}$ cell-associated FoxP3 and IDO, and a treatment-induced increase of tumor-infiltrating T lymphocytes are associated with better clinical efficacy of CTLA-4 blockade. Anti-CTLA-4 therapy enhances the frequency of intratumoral ICOS ${ }^{+} \mathrm{CD}^{+}{ }^{+} \mathrm{T}$ cells that is correlated with better OS. A proportion of these ICOS ${ }^{+} \mathrm{CD}^{+}{ }^{+} \mathrm{T}$ cells is characterized by the production of IFN- $\gamma$. Non-responders to anti-CTLA-4 therapy show a higher percentage of PD-L1- or VISTA-expressing CD4 ${ }^{+} \mathrm{T}$ cells, $\mathrm{CD}^{+} \mathrm{T}$ lymphocytes, and $\mathrm{CD}^{+} 8^{+}$macrophages in posttreatment tumor samples.

(54). In agreement with these findings, it has been reported that PD-L1 expression in at least $50 \%$ of tumor cells correlates with improved efficacy of anti-PD-1 therapy in non-small-cell lung cancer (NSCLC) patients (49). Further clinical trials yielded contradictory results (52). Motzer et al. investigated a large cohort of RCC patients undergoing anti-PD-1 therapy and found a reduced OS for patients with $1 \%$ or greater intratumoral PD-L1 expression compared to patients with less than 1\% (50). Gettinger et al. did also not find a clear correlation between PD-L1 expression and clinical response or survival in anti-PD-1treated NSCLC patients (55). However, the results are not always comparable since various assays, antibodies, cut-off values, and different scoring methods are utilized to determine PD-L1 ${ }^{+}$cells by immunohistochemistry.

\section{Association Between Frequency and Phenotype of Tumor-Infiltrating T Cells and Clinical Efficacy of PD-1/PD-L1 Blockade}

Recent studies revealed that the density and phenotype of tumor-infiltrating $\mathrm{T}$ cells play an essential role for the clinical efficacy of anti-PD-1/PD-L1 therapy. Using melanoma tissue samples collected before and during treatment with anti-PD-1 antibodies, Tumeh et al. determined the frequency of tumorinfiltrating $\mathrm{CD}^{+} \mathrm{T}$ cells (56). A higher density of melanomainfiltrating $\mathrm{CD} 8^{+} \mathrm{T}$ cells at baseline was indicative of responding patients, suggesting that pre-existing intratumoral $\mathrm{CD} 8^{+} \mathrm{T}$ cells are predictors of a clinical response to anti-PD-1 therapy. This finding was further substantiated by another study, investigating RCC tissues from patients treated with anti-PD-L1 and antiVEGF antibodies (57). McDermott et al. found a correlation between a high $\mathrm{T}$ effector gene signature expression at baseline and an improved overall response rate and progression-free survival (PFS) of the treated patients. In contrast, a high myeloid inflammation gene signature expression was associated with reduced PFS in patients receiving anti-PD-L1 alone or antiPD-L1 and anti-VEGF antibodies. When performing an indepth analysis of intratumoral $\mathrm{CD} 8^{+} \mathrm{T}$ lymphocytes in NSCLC patients, Thommen et al. described three distinct $\mathrm{CD}^{+} \mathrm{T}$ cell subsets based on PD-1 expression (58). In addition to $\mathrm{CD}^{+}$ $\mathrm{T}$ cell subpopulations with intermediate $\left(\mathrm{PD}-1^{\mathrm{N}}\right)$ and no $\mathrm{PD}$ 1 expression, a subset with high PD-1 expression $\left(\mathrm{PD}-1^{\mathrm{T}}\right)$ was identified that displayed a markedly different transcriptional and metabolic profile. The $\mathrm{PD}-1^{\mathrm{T}} \mathrm{CD} 8^{+} \mathrm{T}$ cells are characterized by the secretion of CXCL13 that can mediate recruitment of follicular $\mathrm{T}_{\mathrm{H}}$ cells and $\mathrm{B}$ cells to the tumor microenvironment and may also foster the formation of intratumoral tertiary lymphoid structures (TLS). The presence of $\mathrm{PD}-1^{\mathrm{T}} \mathrm{T}$ cells emerged as a strong predictor for the clinical outcome of anti-PD-1-treated NSCLC patients (58).

The impact of anti-PD-1 therapy on the phenotype and frequency of intratumoral $\mathrm{T}$ cells was also explored. Melanoma patients who responded to anti-PD-1 therapy showed an increased intratumoral $\mathrm{CD}^{+} \mathrm{T}$ cell density that was associated with radiographic reduction of tumor size (56). In another study, two major intratumoral $\mathrm{CD}^{+}{ }^{+} \mathrm{T}$ cell states that were associated with clinical response have been identified in melanoma patients treated with PD-1- and/or CTLA-4 blockade (59). Single-cell RNA sequencing resulted in the identification of intratumoral $\mathrm{CD}^{+} \mathrm{T}$ cells with increased expression of genes linked to memory, activation, and cell survival that were enriched in responding melanoma lesions. In contrast, $\mathrm{CD}^{+} \mathrm{T}$ cells with increased expression of genes linked to exhaustion were enriched in non-responding lesions. Thus, the ratio of memory-like to exhausted $\mathrm{CD}^{+} \mathrm{T}$ cells was linked with clinical outcome. In 
addition, elevated levels of melanoma-infiltrating $\mathrm{TCF}^{+} \mathrm{CD} 8^{+}$ $\mathrm{T}$ cells predicted clinical benefit in anti-PD-1-treated patients (59). By using a tumor mouse model, Siddiqui et al. showed that intratumoral $\mathrm{TCF}^{+} \mathrm{PD}-1^{+} \mathrm{CD} 8^{+} \mathrm{T}$ cells with stem-like properties can mediate tumor control to CPI therapy (60). In addition, melanoma patients treated with anti-CTLA-4 and/or anti-PD-1-antibodies showed a higher proportion of intratumoral $\mathrm{TCF}^{+} \mathrm{PD}-1^{+} \mathrm{CD}^{+}{ }^{+} \mathrm{T}$ cells than untreated patients (60). Furthermore, an increased density of $\mathrm{TCF}^{+} \mathrm{PD}-1^{+} \mathrm{CD} 8^{+}$ $\mathrm{T}$ cells at baseline was associated with prolonged survival in melanoma patients treated with anti-CTLA-4 and anti-PD1 -antibodies (61). Moreover, Verma et al. reported that the status of $\mathrm{CD}^{+} \mathrm{T}$ cell priming essentially influences anti-PD1 therapeutic resistance (62). Thus, administration of antiPD-1 antibodies in unprimed or suboptimal primed $\mathrm{CD}^{+}$ $\mathrm{T}$ cell conditions led to the generation of dysfunctional PD$1^{+} \mathrm{CD} 38{ }^{\text {hi }} \mathrm{CD} 8{ }^{+}$cells that contribute to PD- 1 blockade resistance and treatment failure. However, the induction of dysfunctional $\mathrm{CD}^{+}$cells was prevented and treatment resistance was reversed when anti-PD-1 therapy was applied to optimally primed $\mathrm{CD}^{+}{ }^{+} \mathrm{T}$ lymphocytes. They also found that a high density of tumor-infiltrating $\mathrm{PD}-1^{+} \mathrm{CD} 38^{\text {hi }} \mathrm{CD} 8^{+}$cells in melanoma patients can serve as a biomarker of anti-PD-1 resistance. Zappasodi et al. described an intratumoral accumulation of $\mathrm{CD}^{+}{ }^{\text {FoxP }} 3^{-} \mathrm{PD}-1^{\text {hi }} \mathrm{T}$ cells $\left(4 \mathrm{PD}-1^{\text {hi }}\right.$ ) in immunotherapy-naïve melanoma and NSCLC patients (63). These $\mathrm{T}$ cells were shown to inhibit the proliferation and activation of $\mathrm{T}$ effector cells. In addition, the authors found that a lack of effective
$4 \mathrm{PD}-1^{\text {hi }}$ reduction after $\mathrm{PD}-1$ blockade correlates with poor prognosis (63).

\section{Impact of the Frequency of Tumor-Infiltrating B Cells and TLS on Clinical Efficacy of Anti-PD-1 Therapy}

Emerging evidence suggests that tumor-infiltrating B cells play an important role for the clinical outcome of anti-PD-1treated cancer patients. Thus, a higher frequency of melanomainfiltrating $\mathrm{B}$ cells with a plasmablast-like phenotype before therapy was associated with improved patient survival to antiPD-1 treatment (64). More recently, Petitprez et al. observed that the sarcoma immune class $\mathrm{E}$, which is characterized by TLS containing $\mathrm{T}$ cells, follicular DCs, and a high density of B cells, is correlated with an improved response rate and survival to PD-1 blockade (65). In addition, a higher density of tumor-infiltrating B cells and TLS has been detected in treatment responders in a cohort of melanoma patients receiving anti-PD-1-antibodies alone or combined with antiCTLA-4 antibodies in a neoadjuvant setting (66). The importance of tumor-associated TLS for the clinical efficacy of anti-PD1 treatment is further supported by another clinical trial, demonstrating that a higher TLS density at baseline was correlated with increased survival of melanoma patients (67). An overview about immune cell characteristics that may influence the clinical efficacy of anti-PD-1/PD-L1 therapy is given in Figure 2.

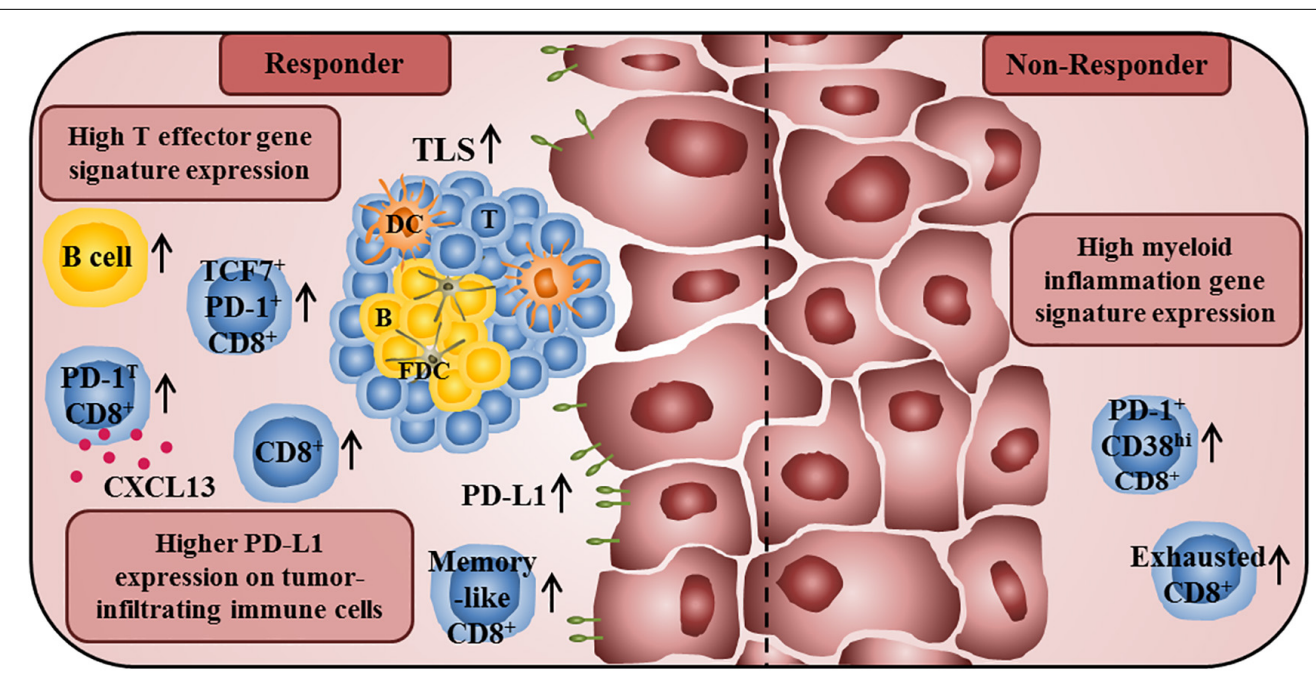

FIGURE 2 | Immune profile of anti-PD-1/PD-L1 antibody-treated tumor patients associated with improved clinical outcome or therapy resistance. A high T effector gene signature expression in pretherapy tumor samples is associated with improved survival of anti-PD-L1- and anti-VEGF-treated cancer patients. In addition, responders to anti-PD-1 treatment show a higher frequency of intratumoral CD8 ${ }^{+} \mathrm{T}$ cells at baseline and an increased frequency of tumor-infiltrating CD8 ${ }^{+} \mathrm{T}_{\text {cells }}$ during therapy. Furthermore, they also have a higher proportion of intratumoral memory-like $\mathrm{CD}^{+}{ }^{\mathrm{T}}$ cells. The presence of PD-1 ${ }^{\top} \mathrm{CD} 8^{+} \mathrm{T}$ cells, which are characterized by a high PD-1 expression and by the capability to secrete CXCL13, is also correlated with improved clinical outcome of anti-PD-1-treated cancer patients. Moreover, an increased frequency of TCF ${ }^{+} \mathrm{PD}-1^{+} \mathrm{CD} 8^{+} \mathrm{T}$ cells in pretreatment tumor samples is associated with prolonged survival in patients treated with anti-CTLA-4 and anti-PD-1-antibodies. An increased density of B cells and TLS, consisting of a DC-containing T cell zone and a follicular DC-containing B cell zone, in pretreatment tumor samples is also correlated with an increased survival of anti-PD-1-treated patients. Furthermore, a higher PD-L1 expression on tumor cells and tumor-infiltrating immune cells is correlated with better clinical responses to anti-PD-1/PD-L1 therapy. In contrast, high frequencies of exhausted CD8 ${ }^{+} T$ cells and PD-1 ${ }^{+} \mathrm{CD} 38^{\text {hi }} \mathrm{CD}^{+}$T cells in tumor tissues are associated with resistance to anti-PD-1 therapy. Non-responders to anti-PD-L1 and anti-VEGF therapy also show a high myeloid inflammation gene expression signature. 


\section{CONCLUSION}

The location, density, and functional orientation of tumorinfiltrating immune cells play a critical role for the clinical outcome of cancer patients. Thus, high frequencies of $\mathrm{CD} 4^{+}$ $\mathrm{T}_{\mathrm{H}} 1$ cells and $\mathrm{CD}^{+} \mathrm{T}$ cells in the tumor center and the invasive margin were associated with improved OS of colorectal cancer patients. Whereas M1 macrophages were correlated with a favorable clinical outcome of cancer patients with various cancer entities, M2 macrophages were generally associated with poor prognosis. Such findings indicate that tumor-infiltrating immune cells can significantly influence tumor growth and spreading. Recent studies revealed that the tumor immune contexture also essentially contributes to the clinical efficacy of CTLA-4 or PD-1/PD-L1 blockade that induced objective clinical responses and improved survival in patients with various tumor types. However, a significant number of patients do not respond to CPI therapy. Therefore, deciphering the immunogenicity of the tumor cells and the tumor immune architecture prior to and during CPI therapy may lead to the discovery of novel modes of action or resistance and to the design of improved treatment modalities for cancer patients. For example, it has been demonstrated that a limited presentation of tumorassociated neoepitopes by tumor cells and the lack of pre-existing

\section{REFERENCES}

1. Fridman WH, Pagès F, Sautès-Fridman C, Galon J. The immune contexture in human tumours: impact on clinical outcome. Nat Rev Cancer. (2012) 12:298-306. doi: 10.1038/nrc3245

2. Gajewski TF, Schreiber H, Fu YX. Innate and adaptive immune cells in the tumor microenvironment. Nat Immunol. (2013) 14:1014-22. doi: 10.1038/ni. 2703

3. Fridman WH, Zitvogel L, Sautès-Fridman C, Kroemer G. The immune contexture in cancer prognosis and treatment. Nat Rev Clin Oncol. (2017) 14:717-34. doi: 10.1038/nrclinonc.2017.101

4. Binnewies M, Roberts EW, Kersten K, Chan V, Fearon DF, Merad M, et al. Understanding the tumor immune microenvironment (TIME) for effective therapy. Nat Med. (2018) 24:541-50. doi: 10.1038/s41591-0180014-x

5. Borst J, Ahrends T, Bąbała N, Melief CJM, Kastenmüller W. CD4+ T cell help in cancer immunology and immunotherapy. Nat Rev Immunol. (2018) 18:635-47. doi: 10.1038/s41577-018-0044-0

6. Galon J, Costes A, Sanchez-Cabo F, Kirilovsky A, Mlecnik B, Lagorce-Pagès C, et al. Type, density, and location of immune cells within human colorectal tumors predict clinical outcome. Science. (2006) 313:1960-4. doi: 10.1126/ science.1129139

7. Pagès F, Kirilovsky A, Mlecnik B, Asslaber M, Tosolini M, Bindea G, et al. In situ cytotoxic and memory T cells predict outcome in patients with earlystage colorectal cancer. J Clin Oncol. (2009) 27:5944-51. doi: 10.1200/JCO. 2008.19.6147

8. Pagès F, Mlecnik B, Marliot F, Bindea G, Ou F-S, Bifulco C, et al. International validation of the consensus Immunoscore for the classification of colon cancer: a prognostic and accuracy study. Lancet. (2018) 391:2128-39. doi: 10.1016/ S0140-6736(18)30789-X

9. Mantovani A, Marchesi F, Malesci A, Laghi L, Allavena P. Tumour-associated macrophages as treatment targets in oncology. Nat Rev Clin Oncol. (2017) 14:399-416. doi: 10.1038/nrclinonc.2016.217

10. Shapouri-Moghaddam A, Mohammadian S, Vazini H, Taghadosi M, Esmaeili S-A, Mardani F, et al. Macrophage plasticity, polarization, and function in health and disease. J Cell Physiol. (2018) 233:6425-40. doi: 10.1002/jcp.26429 intratumoral $\mathrm{T}$ cells are associated with poor responsiveness of cancer patients to CPI therapy. Therefore, other treatment modalities that increase the expression of components of the antigen-processing and presentation machinery and the neoantigen load of tumor cells as well as promote $\mathrm{T}$ cell trafficking to tumor tissues are required to improve the clinical response rate to current CPI therapy. Promising treatment options comprise radiotherapy as well as the application of chemotherapeutic agents and epigenetic drugs that can efficiently increase tumor cell immunogenicity and stimulate antitumor immune responses. Vaccination strategies including neoantigens and the administration of non-modified or engineered $\mathrm{T}$ cells can increase the frequency of tumor-infiltrating and -reactive $\mathrm{T}$ lymphocytes. The intratumoral application of oncolytic viruses or adjuvants can also improve CPI-based therapies by direct tumor cell elimination, the recruitment of DCs and T cells to the tumor, and the activation of innate and adaptive antitumor immunity.

\section{AUTHOR CONTRIBUTIONS}

IP and AT drafted the manuscript. LM, RW, XL, M-OG, SR, MB, and MS reviewed and edited the manuscript.

11. Steinman RM, Banchereau J. Taking dendritic cells into medicine. Nature. (2007) 449:419-26. doi: 10.1038/nature06175

12. Michea P, Noël F, Zakine E, Czerwinska U, Sirven P, Abouzid O, et al. Adjustment of dendritic cells to the breast-cancer microenvironment is subset specific. Nat Immunol. (2018) 19:885-97. doi: 10.1038/s41590-0180145-8

13. Böttcher JP, Bonavita E, Chakravarty $\mathrm{P}$, Blees $\mathrm{H}$, Cabeza-Cabrerizo M, Sammicheli S, et al. NK cells stimulate recruitment of $\mathrm{CDC1}$ into the tumor microenvironment promoting cancer immune control. Cell. (2018) 172:102237.e14. doi: 10.1016/j.cell.2018.01.004

14. Veglia F, Gabrilovich DI. Dendritic cells in cancer: the role revisited. Curr Opin Immunol. (2017) 45:43-51. doi: 10.1016/j.coi.2017.01.002

15. Ahmad F, Döbel T, Schmitz M, Schäkel K. Current concepts on 6-sulfo LacNAc expressing monocytes (slanMo). Front Immunol. (2019) 10:948. doi: 10.3389/ fimmu.2019.00948

16. Toma M, Wehner R, Kloß A, Hübner L, Fodelianaki G, Erdmann K, et al. Accumulation of tolerogenic human 6-sulfo LacNAc dendritic cells in renal cell carcinoma is associated with poor prognosis. Oncoimmunology. (2015) 4:e1008342. doi: 10.1080/2162402X.2015.1008342

17. Havel JJ, Chowell D, Chan TA. The evolving landscape of biomarkers for checkpoint inhibitor immunotherapy. Nat Rev Cancer. (2019) 19:133-50. doi: 10.1038/s41568-019-0116-x

18. Pardoll DM. The blockade of immune checkpoints in cancer immunotherapy. Nat Rev Cancer. (2012) 12:252-64. doi: 10.1038/nrc3239

19. Sharma P, Allison JP. The future of immune checkpoint therapy. Science. (2015) 348:56-61. doi: 10.1126/science.aaa8172

20. Ribas A, Wolchok JD. Cancer immunotherapy using checkpoint blockade. Science. (2018) 359:1350-5. doi: 10.1126/science.aar4060

21. Walunas TL, Lenschow DJ, Bakker CY, Linsley PS, Freeman GJ, Green JM, et al. CTLA-4 can function as a negative regulator of $\mathrm{T}$ cell activation. Immunity. (1994) 1:405-13. doi: 10.1016/1074-7613(94)90071- $\mathrm{x}$

22. Egen JG, Allison JP. Cytotoxic T lymphocyte antigen-4 accumulation in the immunological synapse is regulated by TCR signal strength. Immunity. (2002) 16:23-35. doi: 10.1016/s1074-7613(01)00259-x

23. Chen L. Co-inhibitory molecules of the B7-CD28 family in the control of T-cell immunity. Nat Rev Immunol. (2004) 4:336-47. doi: 10.1038/nri1349 
24. Wing K, Onishi Y, Prieto-Martin P, Yamaguchi T, Miyara M, Fehervari Z, et al. CTLA-4 control over Foxp3+ regulatory T cell function. Science. (2008) 322:271-5. doi: 10.1126/science. 1160062

25. Peggs KS, Quezada SA, Chambers CA, Korman AJ, Allison JP. Blockade of CTLA-4 on both effector and regulatory $\mathrm{T}$ cell compartments contributes to the antitumor activity of anti-CTLA-4 antibodies. J Exp Med. (2009) 206:1717-25. doi: 10.1084/jem.20082492

26. Hodi FS, O’Day SJ, McDermott DF, Weber RW, Sosman JA, Haanen JB, et al. Improved survival with ipilimumab in patients with metastatic melanoma. N Engl J Med. (2010) 363:711-23. doi: 10.1056/NEJMoa100 3466

27. Robert C, Thomas L, Bondarenko I, O'Day S, Weber J, Garbe C, et al. Ipilimumab plus dacarbazine for previously untreated metastatic melanoma. N Engl J Med. (2011) 364:2517-26. doi: 10.1056/NEJMoa1104621

28. Riley RS, June CH, Langer R, Mitchell MJ. Delivery technologies for cancer immunotherapy. Nat Rev Drug Discov. (2019) 18:175-96. doi: 10.1038/s41573018-0006-z

29. Hamid O, Schmidt H, Nissan A, Ridolfi L, Aamdal S, Hansson J, et al. A prospective phase II trial exploring the association between tumor microenvironment biomarkers and clinical activity of ipilimumab in advanced melanoma. J Transl Med. (2011) 9:204. doi: 10.1186/1479-5876-9-204

30. Huang RR, Jalil J, Economou JS, Chmielowski B, Koya RC, Mok S, et al. CTLA4 blockade induces frequent tumor infiltration by activated lymphocytes regardless of clinical responses in humans. Clin Cancer Res. (2011) 17:4101-9. doi: 10.1158/1078-0432.CCR-11-0407

31. Hodi FS, Butler M, Oble DA, Seiden MV, Haluska FG, Kruse A, et al. Immunologic and clinical effects of antibody blockade of cytotoxic $\mathrm{T}$ lymphocyte-associated antigen 4 in previously vaccinated cancer patients. Proc Natl Acad Sci USA. (2008) 105:3005-10. doi: 10.1073/pnas.071223 7105

32. Sharma A, Subudhi SK, Blando J, Scutti J, Vence L, Wargo J, et al. Anti-CTLA-4 immunotherapy does not deplete Foxp3 p regulatory T cells (Tregs) in human cancers. Clin Cancer Res. (2019) 25:1233-8. doi: 10.1158/1078-0432.CCR-180762

33. Liakou CI, Kamat A, Tang DN, Chen H, Sun J, Troncoso P, et al. CTLA-4 blockade increases IFN $\gamma$-producing CD4+ICOS hi cells to shift the ratio of effector to regulatory T cells in cancer patients. Proc Natl Acad Sci USA. (2008) 105:14987-92. doi: 10.1073/pnas.0806075105

34. Wei SC, Levine JH, Cogdill AP, Zhao Y, Anang N-AAS, Andrews MC, et al. Distinct cellular mechanisms underlie anti-CTLA-4 and anti-PD-1 checkpoint blockade. Cell. (2017) 170:1120-33.e17. doi: 10.1016/j.cell.2017.07.024

35. Carthon BC, Wolchok JD, Yuan J, Kamat A, Ng Tang DS, Sun J, et al. Preoperative CTLA-4 blockade: tolerability and immune monitoring in the setting of a presurgical clinical trial. Clin Cancer Res. (2010) 16:2861-71. doi: 10.1158/1078-0432.CCR-10-0569

36. Nowak EC, Lines JL, Varn FS, Deng J, Sarde A, Mabaera R, et al. Immunoregulatory functions of VISTA. Immunol Rev. (2017) 276:66-79. doi: 10.1111/imr.12525

37. Gao J, Ward JF, Pettaway CA, Shi LZ, Subudhi SK, Vence LM, et al. VISTA is an inhibitory immune checkpoint that is increased after ipilimumab therapy in patients with prostate cancer. Nat Med. (2017) 23:551-5. doi: 10.1038/nm. 4308

38. Baumeister SH, Freeman GJ, Dranoff G, Sharpe AH. Coinhibitory pathways in immunotherapy for cancer. Annu Rev Immunol. (2016) 34:539-73. doi: 10.1146/annurev-immunol-032414-112049

39. Francisco LM, Salinas VH, Brown KE, Vanguri VK, Freeman GJ, Kuchroo VK, et al. PD-L1 regulates the development, maintenance, and function of induced regulatory T cells. J Exp Med. (2009) 206:3015-29. doi: 10.1084/jem.20090847

40. Keir ME, Butte MJ, Freeman GJ, Sharpe AH. PD-1 and its ligands in tolerance and immunity. Annu Rev Immunol. (2008) 26:677-704. doi: 10.1146/annurev. immunol.26.021607.090331

41. Dong H, Zhu G, Tamada K, Chen L. B7-H1, a third member of the B7 family, co-stimulates T-cell proliferation and interleukin-10 secretion. Nat Med. (1999) 5:1365-9. doi: 10.1038/70932

42. Latchman Y, Wood CR, Chernova T, Chaudhary D, Borde M, Chernova I, et al. PD-L2 is a second ligand for PD-1 and inhibits T cell activation. Nat Immunol. (2001) 2:261-8. doi: 10.1038/85330
43. Swallow MM, Wallin JJ, Sha WC. B7h, a novel costimulatory homolog of B7.1 and B7.2, is induced by TNFalpha. Immunity. (1999) 11:423-32. doi: 10.1016/s1074-7613(00)80117-x

44. Park J-J, Omiya R, Matsumura Y, Sakoda Y, Kuramasu A, Augustine MM, et al. B7-H1/CD80 interaction is required for the induction and maintenance of peripheral T-cell tolerance. Blood. (2010) 116:1291-8. doi: 10.1182/blood2010-01-265975

45. Keir ME, Liang SC, Guleria I, Latchman YE, Qipo A, Albacker LA, et al. Tissue expression of PD-L1 mediates peripheral T cell tolerance. J Exp Med. (2006) 203:883-95. doi: 10.1084/jem.20051776

46. Dong H, Strome SE, Salomao DR, Tamura H, Hirano F, Flies DB, et al. Tumor-associated B7-H1 promotes T-cell apoptosis: a potential mechanism of immune evasion. Nat Med. (2002) 8:793-800. doi: 10.1038/nm730

47. Fife BT, Pauken KE, Eagar TN, Obu T, Wu J, Tang Q, et al. Interactions between PD-1 and PD-L1 promote tolerance by blocking the TCR-induced stop signal. Nat Immunol. (2009) 10:1185-92. doi: 10.1038/ni.1790

48. Hamid O, Robert C, Daud A, Hodi FS, Hwu W-J, Kefford R, et al. Safety and tumor responses with lambrolizumab (anti-PD-1) in melanoma. N Engl J Med. (2013) 369:134-44. doi: 10.1056/NEJMoa1305133

49. Garon EB, Rizvi NA, Hui R, Leighl N, Balmanoukian AS, Eder JP, et al. Pembrolizumab for the treatment of non-small-cell lung cancer. N Engl J Med. (2015) 372:2018-28. doi: 10.1056/NEJMoa1501824

50. Motzer RJ, Escudier B, McDermott DF, George S, Hammers HJ, Srinivas S, et al. Nivolumab versus everolimus in advanced renal-cell carcinoma. $N$ Engl J Med. (2015) 373:1803-13. doi: 10.1056/NEJMoa1510665

51. Gong J, Chehrazi-Raffle A, Reddi S, Salgia R. Development of PD-1 and PDL1 inhibitors as a form of cancer immunotherapy: a comprehensive review of registration trials and future considerations. J Immunother Cancer. (2018) 6:8. doi: 10.1186/s40425-018-0316-z

52. Nishino M, Ramaiya NH, Hatabu H, Hodi FS. Monitoring immunecheckpoint blockade: response evaluation and biomarker development. Nat Rev Clin Oncol. (2017) 14:655-68. doi: 10.1038/nrclinonc.2017.88

53. Herbst RS, Soria J-C, Kowanetz M, Fine GD, Hamid O, Gordon MS, et al. Predictive correlates of response to the anti-PD-L1 antibody MPDL3280A in cancer patients. Nature. (2014) 515:563-7. doi: 10.1038/nature 14011

54. Topalian SL, Hodi FS, Brahmer JR, Gettinger SN, Smith DC, McDermott DF, et al. Safety, activity, and immune correlates of anti-PD-1 antibody in cancer. N Engl J Med. (2012) 366:2443-54. doi: 10.1056/NEJMoa1200690

55. Gettinger SN, Horn L, Gandhi L, Spigel DR, Antonia SJ, Rizvi NA, et al. Overall survival and long-term safety of nivolumab (Anti-Programmed Death 1 Antibody, BMS-936558, ONO-4538) in patients with previously treated advanced non-small-cell lung cancer. J Clin Oncol. (2015) 33:2004-12. doi: 10.1200/JCO.2014.58.3708

56. Tumeh PC, Harview CL, Yearley JH, Shintaku IP, Taylor EJM, Robert L, et al. PD-1 blockade induces responses by inhibiting adaptive immune resistance. Nature. (2014) 515:568-71. doi: 10.1038/nature13954

57. McDermott DF, Huseni MA, Atkins MB, Motzer RJ, Rini BI, Escudier B, et al. Clinical activity and molecular correlates of response to atezolizumab alone or in combination with bevacizumab versus sunitinib in renal cell carcinoma. Nat Med. (2018) 24:749-57. doi: 10.1038/s41591-018-0053-3

58. Thommen DS, Koelzer VH, Herzig P, Roller A, Trefny M, Dimeloe S, et al. A transcriptionally and functionally distinct PD-1+ CD8+ T cell pool with predictive potential in non-small-cell lung cancer treated with PD-1 blockade. Nat Med. (2018) 24:994-1004. doi: 10.1038/s41591-0180057-z

59. Sade-Feldman M, Yizhak K, Bjorgaard SL, Ray JP, de Boer CG, Jenkins RW, et al. Defining $\mathrm{T}$ cell states associated with response to checkpoint immunotherapy in melanoma. Cell. (2018) 175:998-1013.e20. doi: 10.1016/j. cell.2018.10.038

60. Siddiqui I, Schaeuble K, Chennupati V, Fuertes Marraco SA, Calderon-Copete $\mathrm{S}$, Pais Ferreira D, et al. Intratumoral Tcf1 + PD-1 + CD $8+\mathrm{T}$ cells with stem-like properties promote tumor control in response to vaccination and checkpoint blockade immunotherapy. Immunity. (2019) 50:195-211.e10. doi: 10.1016/j.immuni.2018.12.021

61. Miller BC, Sen DR, Al Abosy R, Bi K, Virkud YV, LaFleur MW, et al. Subsets of exhausted CD8 + T cells differentially mediate tumor control and respond 
to checkpoint blockade. Nat Immunol. (2019) 20:326-36. doi: 10.1038/s41590019-0312-6

62. Verma V, Shrimali RK, Ahmad S, Dai W, Wang H, Lu S, et al. PD-1 blockade in subprimed CD8 cells induces dysfunctional PD-1+CD38hi cells and antiPD-1 resistance. Nat Immunol. (2019) 20:1231-43. doi: 10.1038/s41590-0190441-y

63. Zappasodi R, Budhu S, Hellmann MD, Postow MA, Senbabaoglu Y, Manne S, et al. Non-conventional Inhibitory CD4+Foxp3-PD-1hi T cells as a biomarker of immune checkpoint blockade activity. Cancer Cell. (2018) 33:1017-32.e7. doi: 10.1016/j.ccell.2018.05.009

64. Griss J, Bauer W, Wagner C, Simon M, Chen M, Grabmeier-Pfistershammer K, et al. B cells sustain inflammation and predict response to immune checkpoint blockade in human melanoma. Nat Commun. (2019) 10:4186. doi: 10.1038/ s41467-019-12160-2

65. Petitprez F, de Reyniès A, Keung EZ, Chen TW-W, Sun C-M, Calderaro J, et al. B cells are associated with survival and immunotherapy response in sarcoma. Nature. (2020) 577:556-60. doi: 10.1038/s41586-0191906-8
66. Helmink BA, Reddy SM, Gao J, Zhang S, Basar R, Thakur R, et al. B cells and tertiary lymphoid structures promote immunotherapy response. Nature. (2020) 577:549-55. doi: 10.1038/s41586-019-1922-8

67. Cabrita R, Lauss M, Sanna A, Donia M, Skaarup Larsen M, Mitra S, et al. Tertiary lymphoid structures improve immunotherapy and survival in melanoma. Nature. (2020) 577:561-5. doi: 10.1038/s41586-019-1914-8

Conflict of Interest: The authors declare that the research was conducted in the absence of any commercial or financial relationships that could be construed as a potential conflict of interest.

Copyright (c) 2020 Plesca, Tunger, Müller, Wehner, Lai, Grimm, Rutella, Bachmann and Schmitz. This is an open-access article distributed under the terms of the Creative Commons Attribution License (CC BY). The use, distribution or reproduction in other forums is permitted, provided the original author(s) and the copyright owner(s) are credited and that the original publication in this journal is cited, in accordance with accepted academic practice. No use, distribution or reproduction is permitted which does not comply with these terms. 